\title{
Efeito de extratos de adubos verdes sobre Lactuca sativa e Digitaria horizontalis
}

\author{
Eduardo Andrea Lemus Erasmo ( $\left.{ }^{1}\right)$; Waldeon Reis de Azevedo ( $\left.{ }^{1}\right)$; Neumárcio Vilanova da Costa $\left(2^{*}\right)$; \\ Pedro Luis da Costa Aguiar Alves ( $\left.{ }^{3}\right)$ \\ (1) Universidade Federal do Tocantins (UFT), Departamento de Engenharia Florestal, Caixa Postal 66, 77404-970 Gurupi (TO). \\ (2) UNIOESTE, Centro de Ciências Agrárias, Rua Pernambuco, 1.777, 85960-000 Marechal Cândido Rondon (PR). \\ (3) UNESP, Faculdade de Ciências Agrárias e Veterinárias (FCAV), Rod. Prof. Paulo Donato Castellane, s/n, 14884-900 Jaboticabal (SP). \\ (*) Autor correspondente: neumarciovc@hotmail.com
}

Recebido: 2/Jun./2010; Aceito: 24/ago./2010.

\begin{abstract}
Resumo
Objetivou-se avaliar os efeitos de extratos de quatro espécies de adubos verdes (Canavalia ensiformis, Crotalaria spectabilis, Mucuna aterrima e Sorghum bicolor cv. AG 2005) sobre a germinação de sementes e o crescimento inicial de plântulas de Lactuca sativa e de Digitaria horizontalis. Foram realizados dois experimentos: no primeiro, avaliou-se a aplicação das soluções diluídas a 1\%, 2\%, 3\%, 4\%, 5\% e10\% de extratos aquosos da parte aérea e das raízes das espécies de adubos verdes sobre a germinação, índice de velocidade de germinação e o comprimento radicular de L. sativa; no segundo, avaliou-se a incorporação ao solo de 0, 10, 20, 30, 40 e $50 \mathrm{~g} \mathrm{dm}^{-3}$ da biomassa dos adubos verdes sobre o acúmulo de massa seca (parte aérea e raízes) e o desenvolvimento radicular de plântulas de $L$. sativa e de $D$. horizontalis. Concluiu-se que os extratos aquosos das espécies C. ensiformis, C. spectabilis, M. aterrima e S. bicolor cv. AG 2005 promoveram efeitos negativos sobre a germinação e o IVG das sementes de L. sativa. A incorporação ao solo da biomassa dessas espécies de adubos verdes influenciou negativamente no desenvolvimento inicial das plântulas de L. sativa. Entretanto, verificou-se efeito positivo sobre o desenvolvimento inicial de $D$. horizontalis com a incorporação ao solo da biomassa de C. spectabilis.
\end{abstract}

Palavras-chave: Fabaceae, aleloquímicos, planta daninha, germinação.

\section{Effects of extracts of green manure in Lactuca sativa and Digitaria horizontalis}

\section{Abstract}

This study aimed to evaluate the potential allelopathic effects of four species of green manure (Canavalia ensiformis, Crotalaria spectabilis, Mucuna aterrima and Sorghum bicolor cv. AG 2005) on the seed germination and initial growth of seedlings of Lactuca sativa and Digitaria horizontalis. In the first experiment, the effects of dilute solutions of 1\%, 2\%, 3\%, 4\%, 5\% and 10\% of shoot and root aqueous extracts of green manure were evaluated on germination, speed of germination index (SGI) and root length of $L$. sativa. In the second experiment, the incorporation into the soil of 0, 10, 20, 30, 40 and $50 \mathrm{~g} \mathrm{dm}^{-3}$ of biomass of green manure was evaluated on the accumulation of dry weight (shoots and roots) and root development of seedlings of $L$. sativa and D. horizontalis. In conclusion, the aqueous extracts of the species C. ensiformis, C. spectabilis, M. aterrima and S. bicolor cv. AG 2005 promoted negative allelopathic effects on seed germination and SGI of L. sativa. The incorporation into the soil of the biomass also negatively affected the initial development of seedlings of $L$. sativa. However, there were beneficial allelopathic effects on the early development of D. horizontalis with incorporation into the soil biomass of C. spectabilis.

Key words: Fabaceae, allelochemicals, weed, germination. 


\section{INTRODUÇÃO}

A adubação verde consiste na utilização de plantas em rotação, sucessão ou em consorciação com as culturas, incorporadas ou não ao solo, destacando-se entre estas plantas as fabaceas, em razão da sua capacidade de fixação de nitrogênio atmosférico, da reciclagem de nutrientes e da fácil decomposição da biomassa (TeIXeIra et al., 2004; Favero et al., 2001, Khanh et al., 2005).

A alelopatia de algumas espécies utilizadas como adubos verdes tem sido reconhecida como um importante mecanismo ecológico que influencia na dominância vegetal, na sucessão e na formação de comunidades vegetais, bem como na produtividade e no manejo de culturas agrícolas (Khanh et al., 2005; Goldfarb et al., 2009). Os compostos alelopáticos oriundos do metabolismo secundário da planta são encontradas distribuídos em concentraçóes variadas nas diferentes partes da planta e durante seu ciclo de vida. As principais formas de liberaçáo destes compostos para o ambiente são a volatilizaçâo pelas folhas, decomposição de resíduos vegetais, exsudação pelas raízes e lixiviação por meio de chuva, neblina e orvalho (Souza, 1988; MACíAs et al., 2007).

Extratos aquosos da parte aérea de Crotalaria juncea reduziu a germinação da Lactuca sativa e de Bidens pilosa em cerca de $89,6 \%$ e $35,5 \%$ respectivamente, em consequência de seus efeitos alelopáticos (Teixerra et al., 2004). Efeitos alelopáticos de crotalária (Crotalaria juncea e Crotalaria spectabilis), guandu-anão (Cajanus cajan), leucena (Leucaena leucocephala), mucuna-preta (Stilozobium aterrimum), mucuna-rajada (Stilozobium sp.) e sorgo (Sorghum bicolor) também foram verificados sobre as espécies daninhas Amaranthus hybridus, Amaranthus spinosus, Brachiaria decumbens, Brachiaria plantaginea, Cyperus rotundus, Desmodium adscendens, Desmodium purpureum, Hyptis lophanta, Panicum maximum, Sida rhombifolia e Vernonia polyanthes (Souza Filho et al., 1997; Pires et al., 2001; Severino e Christoffoleti, 2001; Vidal e Trezzi, 2004; Trezzi e Vidal, 2004; FontanÉtTI et al., 2007).

A reduçáo da infestaçáo por plantas daninhas tem ocorrido em áreas que utilizam o sistema de plantios rotacionados com adubos verdes, os quais têm proporcionado inibição por cobertura completa da área ou por manejo de incorporação ao solo (FLECK et al., 1984; SEVERINo e Christofoleti, 2001).

A utilização do potencial alelopático dos adubos verdes como prática de manejo integrado de plantas daninhas em diversas culturas, pode ainda contribuir com a melhoria química e física do solo, principalmente em cerrados (Favero et al., 2001; Erasmo et al., 2004; ANDRADE Neto et al., 2008).

Portanto, a hipótese da pesquisa baseia-se no fato de que a alelopatia de espécies de adubo verdes pode ser decorrente de substâncias presentes na parte aérea e/ou no sistema radicular das plantas, uma vez que existem pou- cas informaçôes sobre em qual parte da planta pode haver maior ação alelopática. Da mesma forma, os efeitos em outras espécies podem estar relacionados com o aumento da concentração das substâncias alelopáticas no solo.

Assim, este trabalho teve como objetivo avaliar os efeitos de extratos da parte aérea e das raízes das espécies utilizadas como adubos verdes Canavalia ensiformis (feijão-de-porco), Crotalaria spectabilis (crotalária), Mucuna aterrima (mucuna-preta) e Sorghum bicolor cv. AG 2005 (sorgo forrageiro) sobre a germinação de sementes e o crescimento inicial de plântulas de Lactuca sativa (alface), utilizada como espécie sensível e de Digitaria horizontalis (capim-colchão).

\section{MATERIAL E MÉTODOS}

Foram realizados, em outubro de 2000, dois experimentos em Jaboticabal (SP), sendo a localização geográfica da área de realização dos experimentos definida pelas coordenadas $21^{\circ} 15^{\prime}$ latitude sul e $48^{\circ} 18^{\prime}$ longitude oeste, com altitude média de $570 \mathrm{~m}$.

No primeiro experimento realizado em condições de laboratório foram avaliados os efeitos dos extratos aquosos da parte aérea e das raízes dos adubos verdes $C$. ensiformis, C. spectabilis, M. aterrima e S. bicolor cv. AG 2005 sobre a germinação, o índice de velocidade de germinação e o comprimento radicular de $L$. sativa. As espécies de adubos verdes foram semeadas em canteiros de $2,0 \times 1,5 \mathrm{~m}$, tendo como substrato $30 \mathrm{~kg}$ de torta de filtro para cada 100 $\mathrm{kg}$ de solo (Latossolo Vermelho) e $150 \mathrm{~kg} \mathrm{ha}^{-1}$ de NPK (5-25-15). Somente o sorgo forrageiro recebeu adubação de cobertura com sulfato de amônia $\left(25 \mathrm{~kg} \mathrm{ha}^{-1} \mathrm{de} \mathrm{N}\right)$ aos 20 dias após a semeadura (DAS). No caso da crotalária, devido ao seu desenvolvimento mais lento em relaçáo às demais espécies de adubos verdes, foi realizada a semeadura em vasos plásticos com capacidade para 5,0 L um mês antes do plantio nos canteiros.

Após 30 DAS, as plantas foram coletadas e sua biomassa lavada em água corrente para se retirar o excesso de impurezas, sendo posteriormente separada a parte aérea das raízes e novamente imergidas em água destilada por 5 minutos. Os adubos verdes com suas partes separadas foram acondicionados em sacos plásticos identificados e logo após armazenados em um congelador a uma temperatura de $5{ }^{\circ} \mathrm{C}$.

Os extratos da parte aérea e das raízes dos adubos verdes foram elaborados conforme metodologia modificada proposta por Gorla e Perez (1997), cortando-se o material em pequenos pedaços separadamente, sendo em seguida triturados em liquidificador com água destilada. Em razão da variação da quantidade de massa verde da parte aérea e de raízes obtidas entre as espécies determinaram-se as seguintes proporçôes de diluição: $C$. ensiformis (1:4 $\mathrm{p} \mathrm{p}^{-1}$ de parte aérea e 1:5 $\mathrm{p} \mathrm{p}^{-1}$ de raízes), C. spectabilis 
(1:9 $\mathrm{p} \mathrm{p}^{-1}$ de parte aérea e $1: 5 \mathrm{p} \mathrm{p}^{-1}$ de raízes), $M$. aterrima (1:4 $\mathrm{p} \mathrm{p}^{-1}$ de parte aérea e $1: 5 \mathrm{p} \mathrm{p}^{-1}$ de raízes) e $S$. bicolor cv. AG 2005 (1:4 $\mathrm{p} \mathrm{p}^{-1}$ de parte aérea e 1:3 $\mathrm{p} \mathrm{p}^{-1}$ de raízes) cujas soluçóes foram consideradas padróes com concentração de $100 \%$.

Os tratamentos utilizados constaram de diluições dessas soluções-padrão em água destilada nas seguintes concentraçóes: $1 \%, 2 \%, 3 \%, 4 \%, 5 \%, 10 \%$ (por exemplo, $1 \%=1 \mathrm{~g}$ do extrato padrão em $100 \mathrm{~g}^{-1}$ de água destilada), tendo ainda uma testemunha (água destilada). Os extratos-padrão com suas devidas diluiçôes foram armazenados em geladeira a $10^{\circ} \mathrm{C}$, até a instalação do experimento.

$\mathrm{O}$ delineamento experimental foi inteiramente casualizado, com três repetições. Para aplicação dos extratos foram utilizadas caixas gerbox, submetidas à pré-lavagem e à assepsia com solução de hipoclorito de sódio na concentração $1 \%$ por 2 horas. Os papéis de germinação foram previamente esterilizados em autoclave a $120^{\circ} \mathrm{C}$ por 20 minutos, sendo colocados nas caixas gerbox e logo em seguida umedecidos com $10 \mathrm{~mL}$ dos respectivos extratos e diluiçôes. Posteriormente, foram acondicionadas 50 sementes de alface e as caixas gerbox foram colocadas em câmara de germinação do tipo CDG, onde permaneceram por um período de 7 dias, à temperatura de $25^{\circ} \mathrm{C}$ e um fotoperíodo de 12 horas. Neste período, realizou-se diariamente o umedecimento do papel de germinaçáo com adiçáo dos respectivos extratos de cada tratamento. No início, foram determinadas a porcentagem de germinação e o índice de velocidade de germinação (IVG) (MAGuire, 1962), e no fim medido o comprimento $(\mathrm{cm})$ das raízes das plântulas de L. sativa.

Para o segundo experimento em casa de vegetação, a biomassa das espécies de adubos verdes (parte aérea e raízes) coletada nos canteiros aos 30 DAS, também foi cortada em pequenos pedaços e incorporados ao solo tipo Latossolo Vermelho e acondicionados em vasos. Foram utilizadas quantidades crescentes de biomassa dos adubos verdes correspondendo a 10,20,30, 40 e $50 \mathrm{~g} \mathrm{dm}^{-3} \mathrm{de}$ solo, além de uma testemunha sem incorporação.

Após a incorporação da biomassa dos adubos verdes C. ensiformis, C. spectabilis, M. aterrima e S. bicolor cv. AG 2005 avaliou-se o acúmulo de massa seca (parte aérea e raízes) e o desenvolvimento radicular de plântulas de $L$. sativa e de $D$. horizontalis.

O delineamento experimental adotado foi o de blocos casualizados, com três repetiçôes. Os vasos plásticos tinham a capacidade de 5,0 L e após a incorporação das biomassas dos adubos verdes ao solo, as superfícies dos vasos foram divididas em duas partes, sendo na primeira semeado $L$. sativa e na segunda $D$. horizontalis. Aos 7 DAS foi realizado o desbaste para a obtenção de um estande de 20 plantas vaso $^{-1}$ (10 plantas de $L$. sativa e 10 plantas de $D$. horizontalis).

Decorridos 20 DAS, foram coletadas todas as plantas, sendo cortada separadamente a parte aérea das raízes das plantas de alface e capim-colchão, bem como mensurado o comprimento $(\mathrm{cm})$ das raízes, e depois acondicionadas em sacos de papel devidamente identificados e posteriormente levados a uma estufa de circulaçáo de ar forçada por 48 horas, à temperatura de $70{ }^{\circ} \mathrm{C}$, para obtençáo da massa seca.

Os dados obtidos foram submetidos à análise de regressão polinomial e não-linear que apresentaram explicação biológica e elevado $\mathrm{R}^{2}$, utilizando-se o programa SigmaStat 2.0, em seguida os gráficos foram confeccionados por meio do programa Excel. Já os dados referentes ao comprimento das raízes do primeiro experimento foram submetidos à análise de variância e as médias comparadas pelo teste de Tukey $(\mathrm{p} \leq 0,05)$.

\section{RESULTADOS E DISCUSSÕES}

\section{Experimento em condição de laboratório}

Os extratos da parte aérea e das raízes de C. ensiformis nas concentraçôes de $1 \%$ a $5 \%$, promoveram tendência de aumento na porcentagem de germinação das sementes de L. sativa. No entanto, os extratos desta espécie promoveram reduçóes na porcentagem de germinação das sementes de $L$. sativa a partir da concentração de $8 \%$, e na concentraçáo de $10 \%$, houve reduçôes em torno de 5,2\% e 4,0\%, respectivamente, para os extratos da parte aérea e das raízes (Figura 1a,b). Estes resultados corroboram com os obtidos por Alves et al. (1998), que verificaram redução na germinação de sementes de Cucumis sativus (pepino) após a exposição a concentraçôes superiores a $2 \%$ de extratos da folha de $C$. ensiformes.

$\mathrm{O}$ extrato aquoso da parte aérea do $C$. ensiformis na concentraçáo de $12 \%$, estimulou em $78,5 \%$ o crescimento de Cyperus rotundus (Carvalho et al., 2002). Entretanto, plantas de $C$. rotundus submetidas a tratamentos com extratos de nódulos de raízes de $C$. ensiformis, tiveram inibiçáo do brotamento dos tubérculos e das folhas cloróticas (Magalhães e Franco, 1962).

A germinação das sementes de L. sativa foi reduzida em $11,0 \%$ em relação à testemunha, a partir da concentração de $1 \%$ do extrato da parte aérea de C. spectabilis, e na concentração de $10 \%$ a redução na germinaçáo foi da ordem de 20,6\% (Figura 1c,d). A concentração de 1\% do extrato das raízes de C. spectabilis promoveu reduçáo de $29,1 \%$ na germinação das sementes de $L$. sativa e para a concentração de $10 \%$ a redução foi em torno de $40,0 \%$.

Os extratos da parte aérea e das raízes do adubo verde $M$. aterrima proporcionaram efeitos semelhantes sobre a germinação das sementes de L. sativa, e a concentração de $10 \%$ de ambos os extratos promoveram as maiores reduçôes na germinação na ordem de 11,7\% e 11,3\% respectivamente (Figura 1e,f).

Os extratos do S. bicolor cv. AG 2005 tiveram influências sobre a germinação das sementes de L. sativa, uma 
(a)

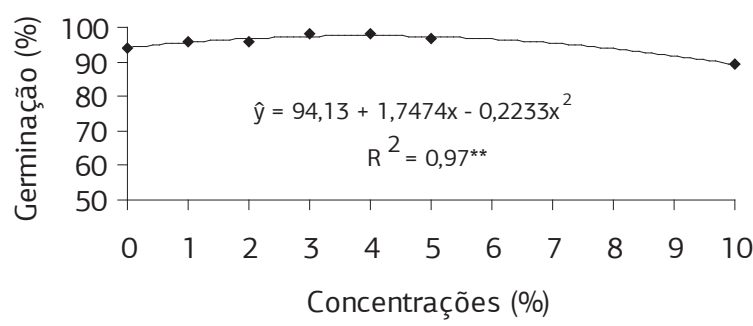

(c)

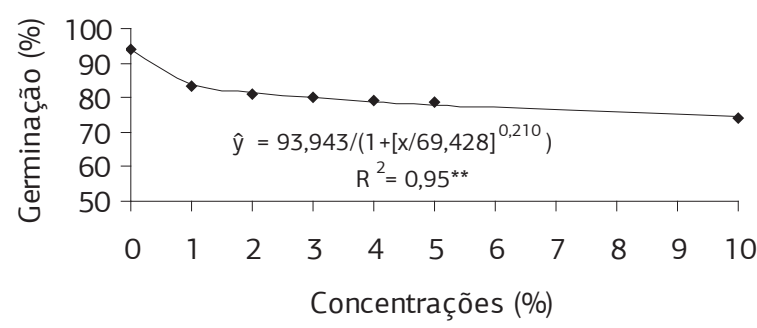

(e)

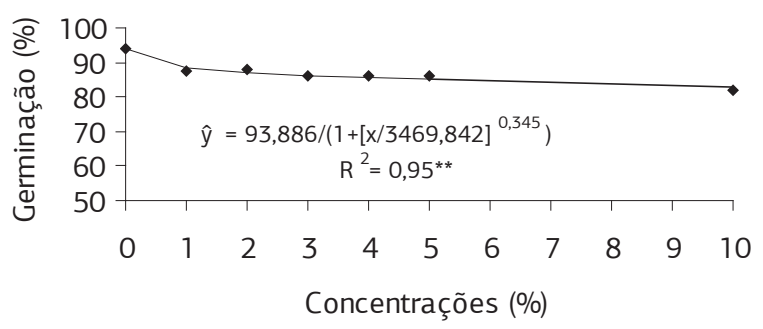

(g)

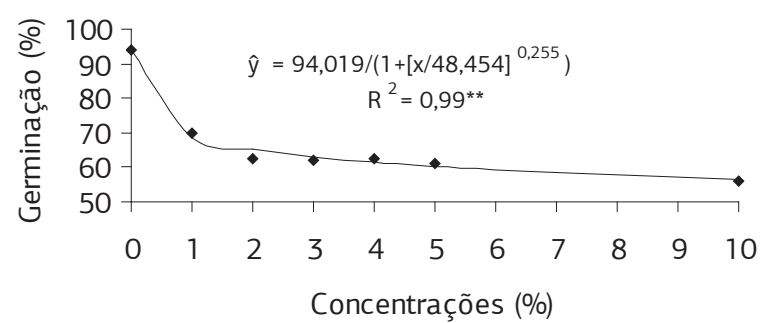

(b)

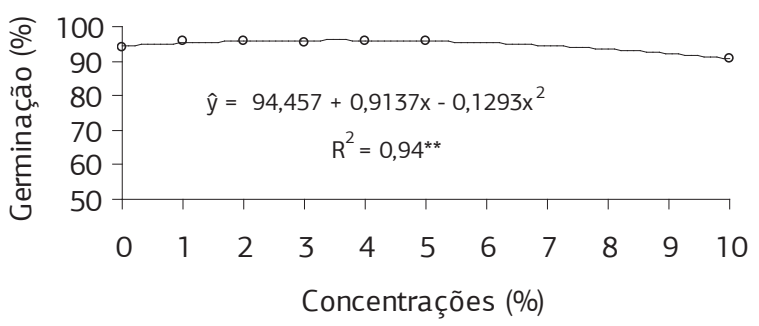

(d)

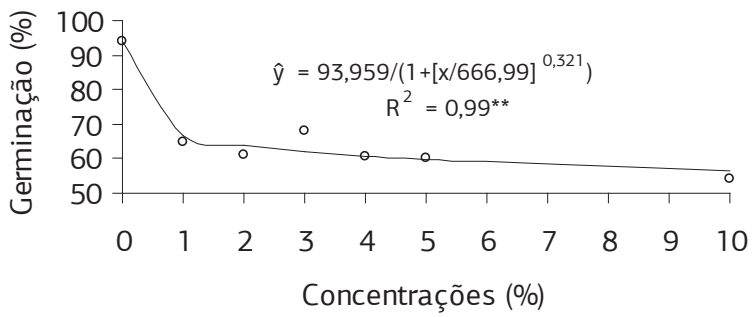

(f)

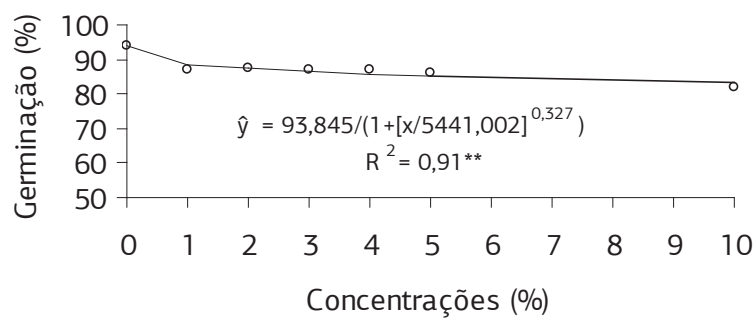

(h)

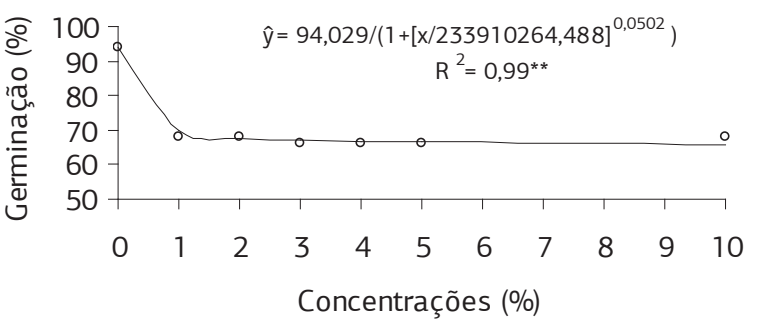

Figura 1. Efeito das concentraçóes dos extratos aquosos da parte aérea e das raízes de C. ensiformis (parte aérea = a; raízes = b), C. spectabilis ( parte aérea $=\mathrm{c}$; raízes $=\mathrm{d}), M$. aterrima $($ parte aérea = e; raízes = f) e S. bicolor cv. AG 2005 (parte aérea = g; raízes = h) sobre a germinação de sementes de L. sativa. Cada símbolo $($ e $\diamond)$ representa o valor médio de três repetiçóes. ${ }^{* *}$ - Significativo pelo teste $\mathrm{F}(\mathrm{p} \leq 0,01)$.

vez que, na concentração de $1 \%$ dos extratos da parte aérea e das raízes, houve reduções de $27,1 \%$ e $27,5 \%$ respectivamente (Figura $1 \mathrm{~g}, \mathrm{~h}$ ). A partir da concentração de $2 \%$ verificou-se que os efeitos dos extratos da parte aérea do adubo verde $S$. bicolor cv. AG 2005 foram mais evidentes em comparação à utilização dos extratos das raízes, sendo em média 10,2\% superior quando se utilizou a concentração de $10 \%$ de ambos os extratos.

Os extratos da parte aérea e das raízes de C. ensiformis não promoveram efeitos sobre o IVG das sementes de $L$. sativa (Figura 2a,b).
Quanto aos efeitos dos extratos das raízes de $C$. spectabilis sobre o IVG das sementes de L. sativa, podese verificar que houve maior efeito inibitório do que quando se utilizaram os extratos da parte aérea (Figura $2 \mathrm{c}, \mathrm{d})$. As reduçôes do IVG promovidas pelas concentraçóes de $1 \%$ a $10 \%$ dos extratos das raízes variaram entre $65,6 \%$ e $73,4 \%$, enquanto, para os extratos da parte aérea na concentração de $10 \%$, houve redução do IVG de 52,1\%. Estes resultados foram semelhantes aos obtidos para os dados de germinação (Figura 1c,d), o que pode indicar maior concentração de substâncias 
(a)

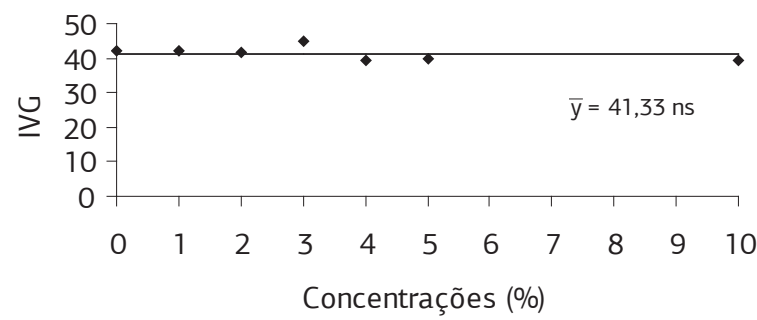

(c)

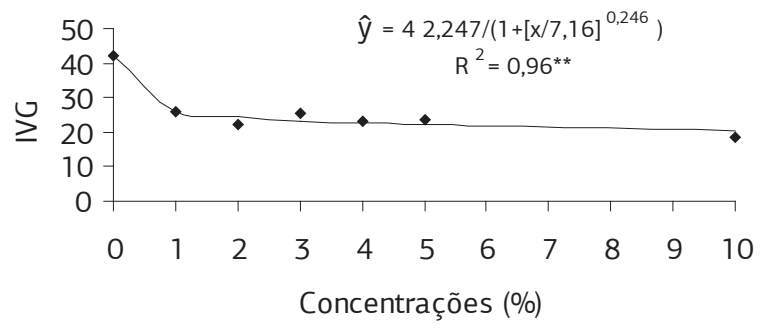

(e)

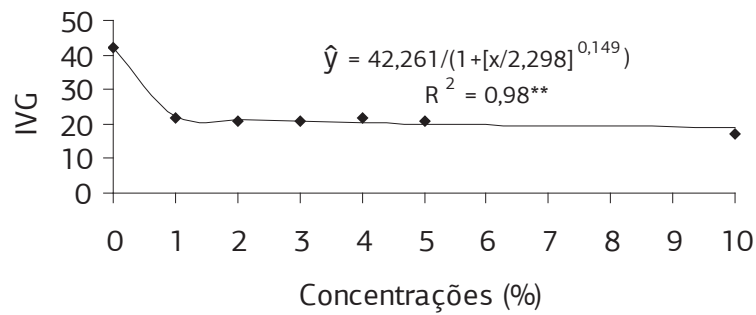

(g)

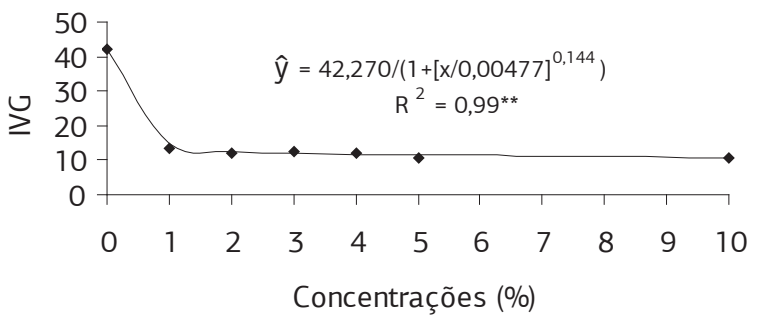

(b)

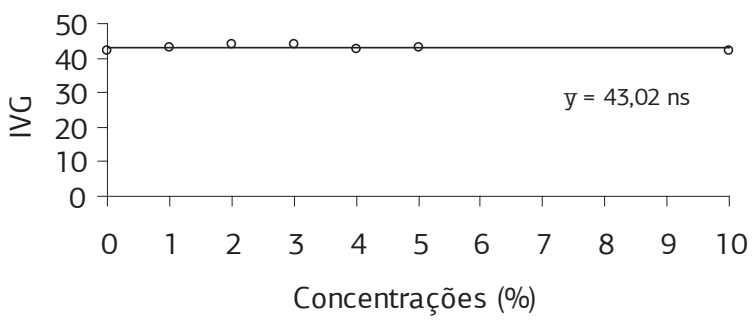

(d)

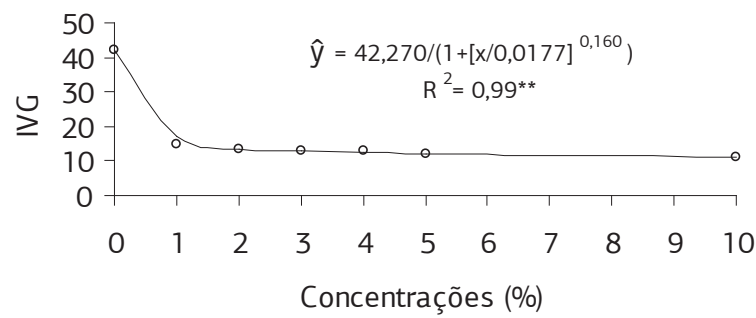

(f)

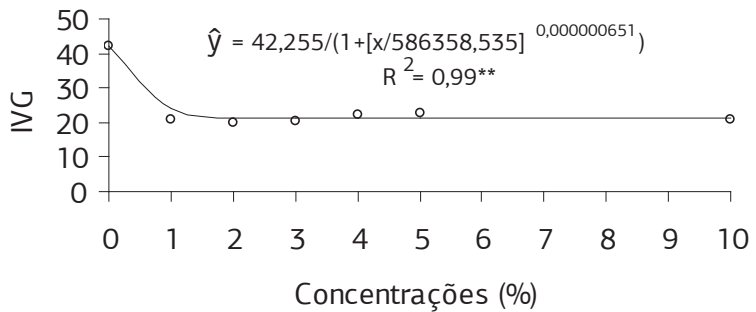

(h)

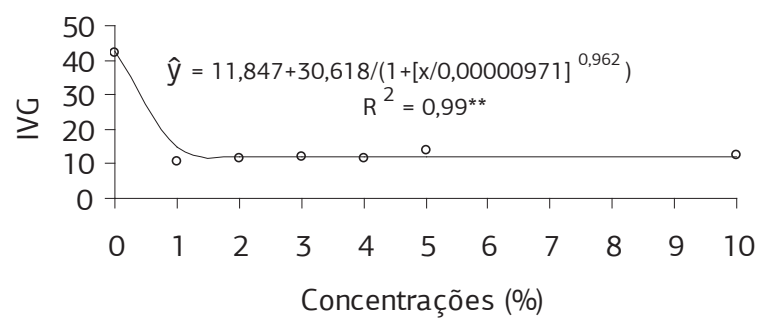

Figura 2. Efeito das concentrações dos extratos aquosos da parte aérea e das raízes de $C$. ensiformis (parte aérea = a; raízes = b), C. spectabilis (parte aérea $=\mathrm{c}$; raízes $=\mathrm{d})$, M. aterrima $($ parte aérea $=\mathrm{e}$; raízes $=\mathrm{f})$ e S. bicolor cv. AG 2005 (parte aérea = g; raízes = h) sobre o índice de velocidade de germinação (IVG) de sementes de L. sativa. Cada símbolo $(\diamond$ e $\diamond)$ representa o valor médio de três repetições. ns: não significativo, ${ }^{* *}$ - Significativo pelo teste $\mathrm{F}(\mathrm{p} \leq 0,01)$.

alelopáticas no sistema radicular em relação à parte aérea de C. spectabilis.

Estes resultados se aproximam dos obtidos por TEIXEIRA et al. (2004), que verificaram redução na ordem de $17,4 \%$ e $39,3 \%$ sobre a germinação e o IVG de sementes de $L$. sativa respectivamente, após a utilização de extrato aquoso da parte aérea de $C$. spectabilis na concentração de $12 \% \mathrm{p} \mathrm{v}^{-1}$.

As respostas foram semelhantes sobre o IVG das sementes de L. sativa após a utilização dos extratos da parte aérea e das raízes de $M$. aterrima, contudo, reduçóes de
$46,9 \%$ e $50,0 \%$ no IVG foram proporcionadas a partir da concentração de $1 \%$ dos extratos da parte aérea e das raízes respectivamente (Figura $2 \mathrm{e}, \mathrm{f}$ ).

$\mathrm{O}$ efeito inibitório dos extratos da parte aérea e das raízes de S. bicolor cv. AG 2005 foi mais expressivo sobre o IVG do que sobre a germinação das sementes de L. sativa. Verificou-se que na concentraçáo de $1 \%$ dos extratos da parte aérea e das raízes houve redução do IVG das sementes de L. sativa na ordem de $68,3 \%$ e $72,1 \%$ respectivamente (Figura 2g,h). 
Os extratos da parte aérea e das raízes de várias espécies do gênero Sorghum são inibidores de germinação e crescimento de plântulas de um grande número espécies (Lehle e Putnam, 1983). Em soja, os extratos aquosos de híbridos de sorgo não interferiram na germinação, no IVG, no comprimento de hipocótilo e na massa seca das plântulas, apenas houve inibição média de 38,2\% do comprimento da radícula da soja (Correia et al., 2005).

Os extratos da parte aérea e das raízes desses adubos verdes avaliados náo exerceram efeitos sobre o comprimento radicular das plântulas de L. sativa (Tabela 1).

\section{Experimento em condição de casa de vegetação}

Foram observados efeitos da incorporação ao solo da biomassa de $C$. ensiformis sobre o acúmulo de massa seca da parte aérea e das raízes de plântulas de $L$. sativa e de D. horizontalis (Figura 3a,b). Nas plântulas de L. sativa ocorreram reduçóes significativas no acúmulo de massa seca da parte aérea e das raízes a partir da incorporação de $10 \mathrm{~g} \mathrm{dm}^{-3}$ de solo da biomassa de C. ensiformis, com médias de $54,3 \%$ e $47,1 \%$ respectivamente. Para a espécie $D$. horizontalis, apenas a massa seca das raízes foi reduzida após a incorporação da biomassa de $C$. ensiformis, e para a incorporaçấo de $20,30,40$ e $50 \mathrm{~g} \mathrm{dm}^{-3}$ os decréscimos foram da ordem de $9,8 \% ; 21,6 \% ; 34,8 \% ; 47,1 \%$ respectivamente.

Houve decréscimos no acúmulo de massa seca da parte aérea e das raízes das plântulas de $L$. sativa e $D$. horizontalis, após a incorporação ao solo da biomassa de $C$. spectabilis (Figura 3c,d). Para L. sativa observaram reduçôes superiores a 13,0\% na massa seca da parte aérea e das raízes a partir da incorporação de, respectivamente, 10 e $20 \mathrm{~g} \mathrm{dm}^{-3}$ da biomassa de C. spectabilis.
Para $D$. horizontalis houve incremento no acúmulo de massa seca da parte aérea de até $72,4 \%$, tendo a incorporaçáo ao solo de $30 \mathrm{~g} \mathrm{dm}^{-3}$ da biomassa de C. spectabilis. Entretanto, este efeito não foi verificado para a massa seca das raízes, uma vez que a incorporação ao solo da biomassa de C. spectabilis promoveu reduçóes em torno de $60,0 \%$ sob a maior quantidade de biomassa.

A massa seca da parte aérea das plântulas de $L$. sativa foi reduzida após a incorporação ao solo da biomassa de M. aterrima em torno de $16,8 \%$ para a quantidade de 10 $\mathrm{g} \mathrm{dm}^{-3}$ de biomassa e cerca de $50,0 \%$ para a maior quantidade de biomassa de $M$. aterrima (Figura 3e,f).

A incorporaçáo ao solo da biomassa de S. bicolor cv. AG 2005 não promoveu reduções na massa seca da parte aérea das plântulas de $D$. horizontalis (Figura $3 \mathrm{~g}, \mathrm{~h}$ ), apenas houve reduçôes superiores a $37,5 \%$ na massa seca das raízes a partir da quantidade de $10 \mathrm{~g} \mathrm{dm}^{-3}$. Houve reduçóes superiores a $27,0 \%$ e $10,4 \%$ na massa seca da parte aérea e das raízes das plântulas de $L$. sativa respectivamente.

O comprimento radicular das plântulas de $L$. sativa e $D$. horizontalis também foi comprometido após a incorporação ao solo da biomassa a partir de $10 \mathrm{~g} \mathrm{dm}^{-3}$ de C. ensiformis, com reduçôes superiores a 7,4 e $4,1 \mathrm{~cm}$ respectivamente (Figura 4a,b). O comprimento radicular das plântulas de $L$. sativa e $D$. horizontalis foi reduzido respectivamente, em 3,8 e 1,7 cm sob incorporaçáo ao solo de $10 \mathrm{~g} \mathrm{dm}^{-3} \mathrm{da}$ biomassa de C. spectabilis, enquanto na maior quantidade de biomassa incorporada os decréscimos foram em torno de 9,9 e 11,4 cm respectivamente (Figura 4c,d).

Para L. sativa, o comprimento das raízes atingiu cerca de 3,0 e 7,0 cm inferior, considerando a menor e a maior quantidade de biomassa de $M$. aterrima incorporada ao solo respectivamente (Figura 4e,f). Para D. horizontalis a redução do comprimento radicular foi superior a $3,0 \mathrm{~cm}$ a partir da incorporação de $20 \mathrm{~g} \mathrm{dm}^{-3}$ de biomassa de $M$. aterrima, e para a quantidade de $50 \mathrm{~g} \mathrm{dm}^{-3}$ a redução foi em média

Tabela 1. Efeito das concentrações dos extratos aquosos da parte aérea e das raízes dos adubos verdes avaliados sobre o comprimento radicular das plântulas de L. sativa

\begin{tabular}{|c|c|c|c|c|c|c|c|c|}
\hline \multirow{2}{*}{ Concentrações } & \multicolumn{2}{|c|}{ C. ensiformis } & \multicolumn{2}{|c|}{ C. spectabilis } & \multicolumn{2}{|c|}{ M. aterrima } & \multicolumn{2}{|c|}{ S. bicolor cv. AG 2005} \\
\hline & Parte Aérea & Raízes & Parte Aérea & Raízes & Parte Aérea & Raízes & Parte Aérea & Raízes \\
\hline$\%$ & \multicolumn{8}{|c|}{ Comprimento $(\mathrm{cm})$} \\
\hline 0 & 3,713 & 3,713 & 3,713 & 3,713 & 3,713 & 3,713 & 3,713 & 3,713 \\
\hline 1 & 3,512 & 3,226 & 3,418 & 3,695 & 3,492 & 3,615 & 3,396 & 3,714 \\
\hline 2 & 3,447 & 3,300 & 3,196 & 3,428 & 3,247 & 3,612 & 3,422 & 3,731 \\
\hline 3 & 3,772 & 3,191 & 3,408 & 3,436 & 3,754 & 3,715 & 3,715 & 3,649 \\
\hline 4 & 3,633 & 3,792 & 3,563 & 3,202 & 3,560 & 3,752 & 3,217 & 3,649 \\
\hline 5 & 3,943 & 3,226 & 3,783 & 3,876 & 3,642 & 3,731 & 3,314 & 3,749 \\
\hline 10 & 3,944 & 3,548 & 3,638 & 3,443 & 3,585 & 3,715 & 3,566 & 3,847 \\
\hline $\mathrm{F}_{\text {Tratamento }}$ & $3,27^{\text {ns }}$ & $3,35^{\text {ns }}$ & $1,48^{\text {ns }}$ & $2,20^{\mathrm{ns}}$ & $0,70^{\text {ns }}$ & 0,90 ns & $1,02^{\text {ns }}$ & $0,12^{\text {ns }}$ \\
\hline D.M.S. & 0,51 & 0,66 & 0,80 & 0,74 & 0,97 & 0,28 & 0,92 & 0,93 \\
\hline C.V. (\%) & 5,02 & 6,97 & 8,22 & 7,53 & 9,76 & 2,79 & 9,54 & 9,05 \\
\hline
\end{tabular}

As médias na coluna não diferiram entre si estatisticamente pelo teste de Tukey ( $\mathrm{p} \leq 0,05)$. ns: não significativo. 
(a)

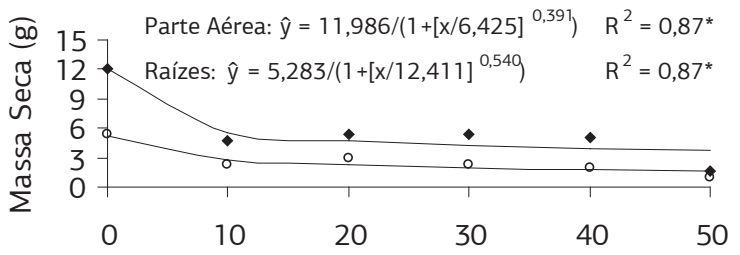

Biomassa Incorporada ao Solo $\left(\mathrm{g} \mathrm{dm}^{-3}\right.$ )

(c)

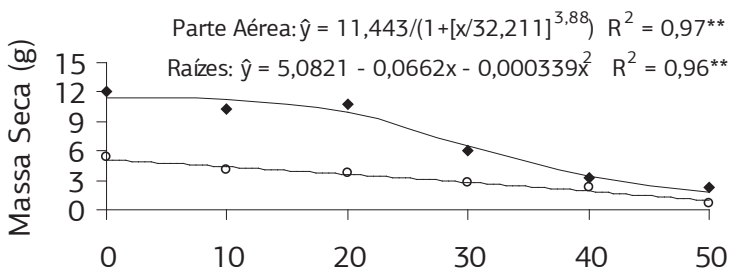

Biomassa Incorporada ao Solo $\left(\mathrm{g} \mathrm{dm}^{-3}\right.$ )

(e)

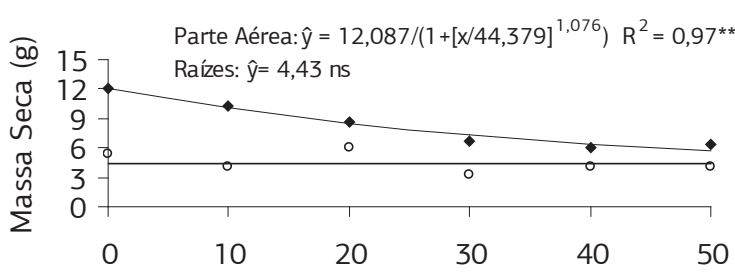

Biomassa Incorporada ao Solo $\left(\mathrm{g} \mathrm{dm}^{-3}\right)$

(g)

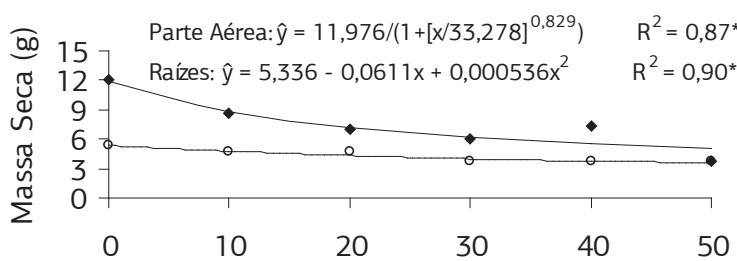

Biomassa Incorporada ao Solo $\left(\mathrm{g} \mathrm{dm}^{-3}\right)$ (b)

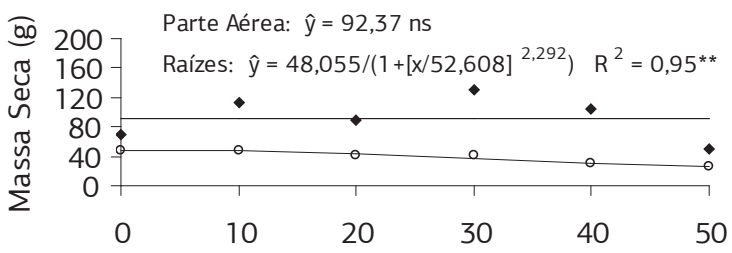

Biomassa Incorporada ao Solo $\left(\mathrm{g} \mathrm{dm}^{-3}\right)$

(d)

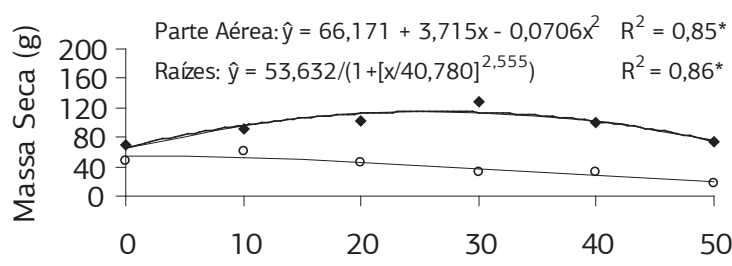

Biomassa Incorporada ao Solo $\left(\mathrm{g} \mathrm{dm}^{-3}\right.$ )

(f)

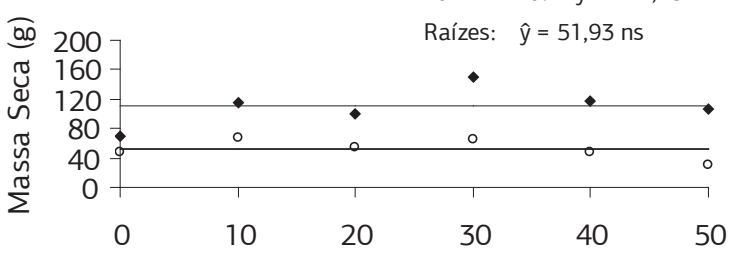

Biomassa Incorporada ao Solo $\left(\mathrm{g} \mathrm{dm}^{-3}\right)$

(h)

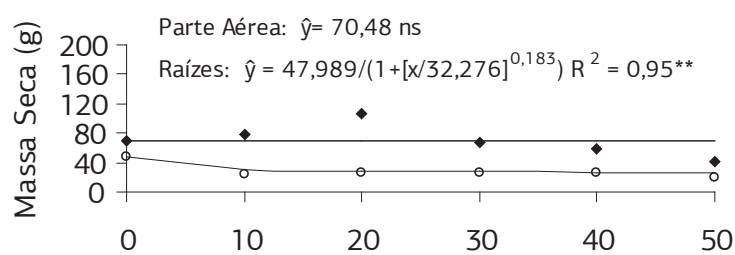

Biomassa Incorporada ao Solo $\left(\mathrm{g} \mathrm{dm}^{-3}\right)$

Figura 3. Efeito da incorporação ao solo da biomassa de C. ensiformis (a, b), c. spectabilis (c, d), M. aterrima (e, f) e S. bicolor cv. AG 2005 (g, h) sobre a massa seca da parte aérea e das raízes das plântulas de L. sativa (a, c, e, g) e D. horizontalis (b, d, f, h). Cada símbolo ( Parte aérea e $\diamond$ Sistema radicular) representa o valor médio de três repetiçóes. ns - não significativo, * - Significativo pelo teste $\mathrm{F}$ ( $\mathrm{p} \leq 0,05)$, ** Significativo pelo teste F $(\mathrm{p} \leq 0,01)$.

de 10,2 cm. O comprimento radicular das plântulas de $L$. sativa e de $D$. horizontalis foram reduzidos em média 3,0 $\mathrm{cm}$, após a incorporação ao solo de $10 \mathrm{~g} \mathrm{dm}^{-3} \mathrm{da}$ biomassa de S. bicolor cv. AG 2005 e de 7,2 e 13,6 cm sob efeito da biomassa de $50 \mathrm{~g} \mathrm{dm}^{-3}$ respectivamente (Figura 4g,h).

A proteção do solo com a biomassa dos adubos verdes C. ensiformis, C. spectabilis, M. aterrima e S. bicolor cv. BR 304 pode reduzir a infestação de plantas daninhas, em média, de $25,9 \% ; 29,5 \% ; 61,8 \%$ e $55,1 \%$ respectivamente (Erasmo et al., 2004). Em áreas que permaneceram 56 dias protegidas por $4 \mathrm{t} \mathrm{ha}^{-1}$ de palha de diferentes genótipos de sorgo, houve redução em $93,6 \%$ e $86,1 \%$ nas infestaçóes de B. plantaginea e S. rhombifolia respectivamente, em relaçáo a áreas sem a presença de palha na superfície do solo (Trezzi e VIdal, 2004). A presença de resíduos da parte aérea das plantas de sorgo causou mais inibição das plantas daninhas do que os resíduos de raízes. Esse fato pode ser decorrente da baixa persistência e mobilidade no solo dos compostos de exudatos radiculares e, provavelmente, sua ação se restrinja à região próxima às raízes das plantas de sorgo (Trezzi e Vidal, 2004; KoBAYAShi, 2004; Demuner et al., 2005). 
(a)

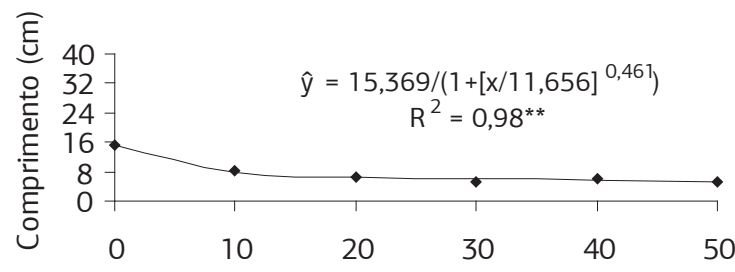

Biomassa Incorporada ao Solo $\left(\mathrm{g} \mathrm{dm}^{-3}\right)$

(c)

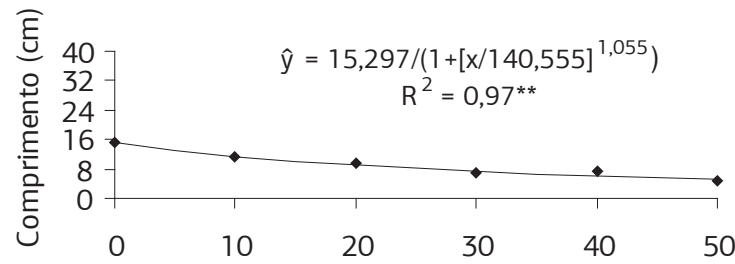

Biomassa Incorporada ao Solo $\left(\mathrm{g} \mathrm{dm}^{-3}\right)$

(e)

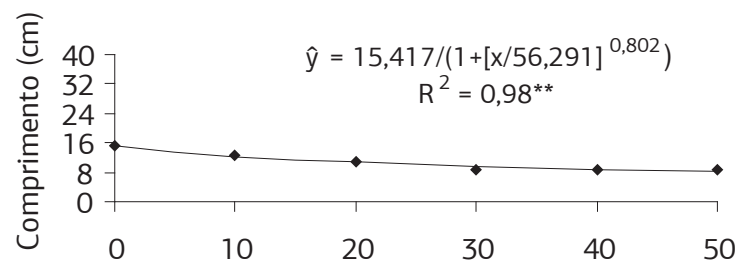

Biomassa Incorporada ao Solo $\left(\mathrm{g} \mathrm{dm}^{-3}\right)$

(g)

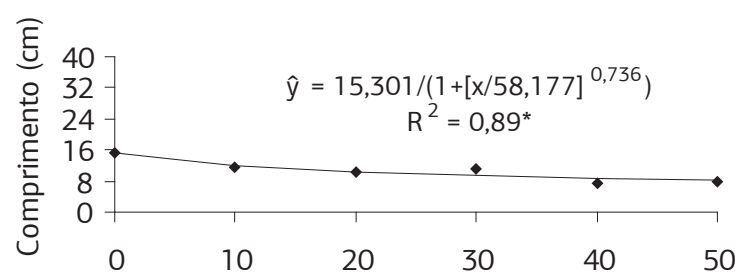

Biomassa Incorporada ao Solo $\left(\mathrm{g} \mathrm{dm}^{-3}\right)$ (b)

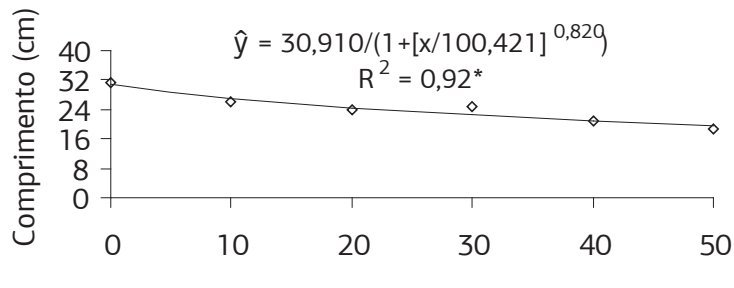

Biomassa Incorporada ao Solo $\left(\mathrm{g} \mathrm{dm}^{-3}\right)$

(d)

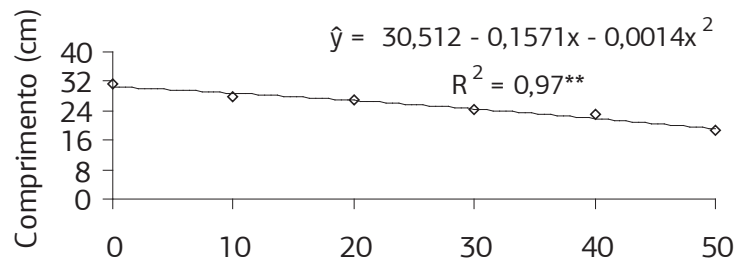

Biomassa Incorporada ao solo $\left(\mathrm{g} \mathrm{dm}^{-3}\right)$

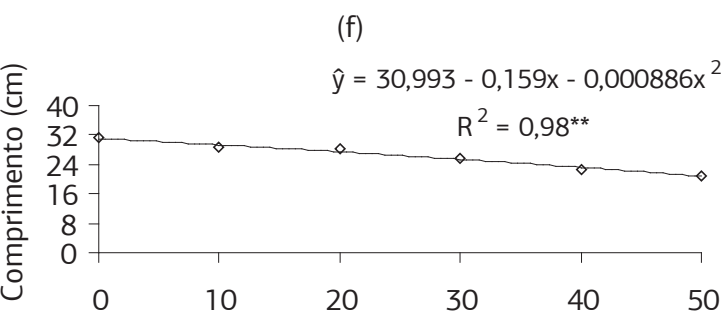

Biomassa Incorporada ao Solo $\left(\mathrm{g} \mathrm{dm}^{-3}\right)$

(h)

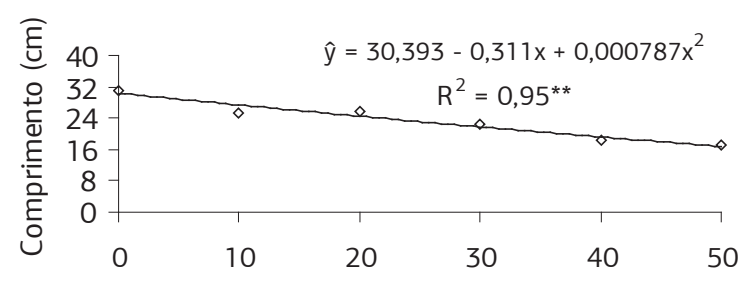

Biomassa Incorporada ao Solo $\left(\mathrm{g} \mathrm{dm}^{-3}\right.$ )

Figura 4. Efeito da incorporação ao solo da biomassa de C. ensiformis (a, b), C. spectabilis (c, d), M. aterrima (e, f) e S. bicolor cv. AG 2005 $(\mathrm{g}, \mathrm{h})$ sobre o comprimento radicular das plântulas de L. sativa (a, c, e, g) e D. horizontalis (b, d, f, h). Cada símbolo $(\downarrow$ e $\diamond)$ representa o valor médio de três repetiçóes. ns: não significativo, *: Significativo pelo teste F ( $\mathrm{p} \leq 0,05)$; ${ }^{* *}$ : Significativo pelo teste $\mathrm{F}(\mathrm{p} \leq 0,01)$.

Ressalta-se que devem ser realizados estudos que avaliem processos como absorçáo, biotransformação, persistência e degradação dos compostos aleloquímicos em condiçôes de campo (Belz, 2007; Macías et al., 2007). Contudo, poderão ser desenvolvidos novos herbicidas menos agressivos ao ambiente, e de culturas com potencial alelopático mais tolerantes a interferência de plantas daninhas. A exploração dos compostos aleloquímicos pode colaborar no manejo integrado das plantas daninhas, contribuindo significativamente para o desenvolvimento de uma agricultura sustentável com redução de aplicações de herbicidas em agrossistemas convencionais (Wu et al., 1999).

\section{CONCLUSÃO}

Os extratos aquosos da parte aérea e das raízes dos adubos verdes promovem efeitos negativos sobre a germinação das sementes de L. sativa.

Somente os extratos aquosos da parte aérea e das raízes de $C$. ensiformis não promovem efeitos negativos sobre o IVG das sementes de L. sativa.

Não há efeito alelopático sobre o comprimento radicular das plântulas de L. sativa, desenvolvidas em contato com os extratos aquosos dos adubos verdes. 
A incorporação ao solo da biomassa das espécies desses adubos verdes pode influenciar negativamente o desenvolvimento inicial das plântulas de L. sativa. Entretanto, para $D$. horizontalis há incremento no acúmulo de massa seca da parte aérea com a incorporação ao solo da biomassa de C. spectabilis.

\section{REFERÊNCIAS}

ALVES, P.L.C.A.; DINARDO, W.; PELEGRINI, M.T. Inhibitory effects of jackbean (Canavalia ensiformes) leaf residues on germination and vigour of crops and weeds. Allelopathy Journal, v.5, p.35-42, 1998.

ANDRADE NETO, R.C.; GÓES, G.B.; MIRANDA, N.O.; FILHO, E.T.O.; FILHO, E.T.D.; FILHO, F.S.T.P. Adubação verde uma alternativa sustentável para o Brasil. Revista Verde, v.3, p.16-20, 2008.

BELZ, R.G. Allelopathy in crop/weed interactions - an update. Pest Management Science, v.63, p.308-326, 2007.

CARVALHO, G.; FONTANÉTTI, A.; CANÇADO, C.T. Potencial alelopático do feijáo de porco (Canavalia ensiformes) e da mucuna preta (Stilozobium aterrimum) no controle da tiririca (Cyperus rotandus). Ciência e Agrotecnologia. v.26, p.647-651, 2002.

CORREIA, N.M.; CENTURION, M.A.P.C.; ALVES, P.L.C.A. Influência de extratos aquosos de sorgo sobre a germinação e o desenvolvimento de plântulas de soja. Ciência Rural, v.35, p.498$503,2005$.

DEMUNER, A.J.; BARBOSA, L.C.A.; CHINELATTO JUNIOR, L.S.; ANTONIO, C.R.; SILVA, A.A. Sorção e persistência da sorgoleona em um latossolo vermelho-amarelo. Química Nova, v.28, p.451-455, 2005.

ERASMO, E.A.L., AZEVEDO, W.R., SARMENTO, R.A. CUNHA, A.M.; GARCIA, S.L.R. Potencial de espécies utilizadas como adubo verde no manejo integrado de plantas daninhas. Planta Daninha, v.22, p.337-342, 2004.

FAVERO, C.; JUCKSCH, I.; ALVARENGA, R.C. Modificaçôes na população de plantas espontâneas na presença de adubos verdes. Pesquisa Agropecuária Brasileira, v.36, p.1355-1362, 2001.

FLECK, N.G.; MACHADO, C.M.N.; SOUZA, R.S. Eficiência da consorcição de culturas no controle de plantas daninhas. Pesquisa Agropecuária Brasileira, v.19, p.591-598, 1984.

FONTANÉTTI, A.; CARVALHO, G.J.; GOMES, L.A.A.; ALMEIDA, K.; MORAES, S.R.G.; DUARTE, W.F. Efeito alelopático da adubação verde no controle de tiririca (Cyperus rotundus L.). Revista Brasileira de Agroecologia, v.2, p.1365-1368, 2007.

GOLDFARB, M.; PIMENTEL, L.W.; PIMENTEL, N.W. Alelopatia: relações nos agroecossistemas. Tecnologia e Ciência Agropecuária, v.3, p.23-28, 2009.

GORLA, C.M.; PEREZ, S.C.J.G.A. Influência de extratos aquosos de folhas de Miconia albicans Triana, Lantana camara L., Leucaena leucocephala (Lam) de Wit e Drimys winteri Forst, na germinação e crescimento inicial de sementes de tomate e pepino. Revista Brasileira de Sementes, v.19, p.260-265, 1997.

KHANH, T.D.; CHUNG, M.I.; XUAN, T.D.; TAWATA, S. The exploitation of crop allelopathy in sustainable agricultural production. Journal of Agronomy and Crop Science, v.191, p.172184, 2005.

KOBAYASHI, K. Factors affecting phytotoxic activity of allelochemicals in soil. Weed Biology and Management, v.4, p.1-7, 2004.

LEHLE, F.R.; PUTNAM, A.R. Allelopathic potencial of sorghum (Sorghum bicolor): isolation of seed germination inhibitors. Journal of Chemical Ecology, v.9, p.1223-1234, 1983.

MACÍAS, F.A.; MOLINILLO, J.M.G.; VARELA, R.M.; GALINDO, J.C.G. Allelopathy - a natural alternative for weed control. Pest Management Science, v.63, p.327-348, 2007.

MAGALHÁES, A.C.; FRANCO, C.M. Toxidade do feijão de porco sobre a "Tiririca". Bragantia, v.21, p.53-58, 1962.

MAGUIRE, J.D. Sped of germination-aid in selection and evolution for seedling emergence and vigor. Crop Science, v.2, p.176-177, 1962 .

PIRES, N.M.; PRATES, H.T.; FILHO, I.A.P.; OLIVEIRAJUNIOR, R.S.; FARIA, T. C.L. Atividade alelopática da leucena sobre espécies de plantas daninhas. Scientia Agricola, v.58, p.61-65, 2001.

SEVERINO, F.J.; CHRISTOFOLETI, P.J. Efeitos de quantidades de fitomassa de adubos verdes na supressão de plantas daninhas. Planta Daninha, v.19, p.223-228, 2001

SOUZA, I.F. Alelopatia de plantas daninhas. Informe Agropecuário, v.13, p.75-78, 1988

SOUZA FILHO, A.P.S.; RODRIGUES, L.R.A.; RODRIGUES, T.J.D. Efeitos do potencial alelopático de três leguminosas forrageiras sobre três invasoras de pastagens. Pesquisa Agropecuária Brasileira, v.32, p.165-170, 1997.

SOUZA FILHO, A.P.S.; RODRIGUES, L.R.A.; RODRIGUES, T.J.D. Efeitos do potencial alelopático de três leguminosas forrageiras sobre três invasoras de pastagens. Pesquisa Agropecuária Brasileira, v.32, p.165-170, 1997.

TEIXEIRA, C.M.; ARAÚJO, J.B.S.; CARVALHO, G.J. Potencial alelopático de plantas de cobertura no controle de picão-preto (Bidens pilosa L.) Ciência e Agrotecnologia, v.28, p.691-695, 2004.

TREZZI, M.M.; VIDAL, R.A. Potencial de utilização de cobertura vegetal de sorgo e milheto na supressão de plantas daninhas em condição de campo: II - efeitos da cobertura morta. Planta Daninha, v.22, p.1-10, 2004.

VIDAL, R.A.; TREZZI, M.M. Potencial da utilização de coberturas vegetais de sorgo e milheto na supressão de plantas daninhas em condição de campo: I - plantas em desenvolvimento vegetativo. Planta Daninha, v.22, p.217-223, 2004.

WU, H.; PRATLEY, J.; LEMERLE, D.; HAIG, T. Crop cultivars with allelopathic capability. Weed Research, v.39, p.171-180, 1999. 